\title{
Use of Preplaced Casting Method in Lightweight Aggregate Concrete
}

\author{
Qiang Du, ${ }^{1}$ Qiang Sun, ${ }^{1}$ Jing Lv, ${ }^{1}$ and Jian Yang ${ }^{2}$ \\ ${ }^{1}$ School of Civil Engineering, Chang'an University, Xian, Shaanxi 710061, China \\ ${ }^{2}$ School of Civil Engineering, Birmingham University, Birmingham B15 2TT, UK \\ Correspondence should be addressed to Qiang Du; q.du@chd.edu.cn
}

Received 21 December 2016; Accepted 15 March 2017; Published 27 March 2017

Academic Editor: Andres Sotelo

Copyright (c) 2017 Qiang Du et al. This is an open access article distributed under the Creative Commons Attribution License, which permits unrestricted use, distribution, and reproduction in any medium, provided the original work is properly cited.

\begin{abstract}
This study addresses the use of preplaced casting method in lightweight aggregate concrete (LC) to provide a new perspective to solve the aggregate segregation. In casting preplaced lightweight aggregate concrete (PLC), the lightweight aggregates are cast into formworks and then fresh grout is injected to fill voids. PLC and conventional lightweight aggregate concrete (CLC) with three different mixtures are compared to observe the degree of segregation. The properties of PLC and CLC are characterized by means of cubic and axial compression, splitting tension and flexural tests, static modulus of elasticity, and drying shrinkage measurements. Results show that the mechanical properties of PLC are improved with respect to that of CLC with the same mixture. The increase of shrinkage is approximately $13 \%$ for the CLC and $6 \%$ for PLC when w/c ratio ranges from 0.4 to 0.5 due to effect on interlocking. PLC shows an increased tendency in elastic modulus by approximately $2.5 \%$ of $0.5 \mathrm{w} / \mathrm{c}$ ratio, $2.7 \%$ of $0.45 \mathrm{w} / \mathrm{c}$ ratio, and $3.3 \%$ of 0.4 $\mathrm{w} / \mathrm{c}$ ratio at the age of 28 days compared with CLC. In conclusion, PLC has significant reduction in the weight on the premise that it shows excellent mechanical properties.
\end{abstract}

\section{Introduction}

Lightweight aggregate concrete (LC) is known by its improved advantage of lightweight antiseismic performance, fire resistance, thermal-insulation, and sustainable development. With the development of high-rise buildings, long span structures, more replacing conventional aggregates with lightweight, and recycled composites are constantly focused on [1-3]. The application of LC has been also investigated and used in recent years [4-7].

Nevertheless, some limits in its engineering properties prevented its wider application. A major problem that affects fresh LC is the tendency for light aggregates with small densities to float from the mortar during the vibrating process and on the stationary state, which decreases uniformity and has greater variability in properties [8]. Therefore, the degree of heterogeneity of LC is the key difficulty to improve mechanical behavior and durability. Many researchers contributed to analysis on segregation resistance. In terms of physical properties of lightweight aggregate, $\mathrm{Li}$ and Ding studied five different types of lightweight aggregate and investigated the volume quantity, vibrating time, and the characters of lightweight aggregate including shape, surface smoothness, and water absorption [9]. It is also recommended by several researchers to apply the method of mix design for LC to avoid the material segregation. Such mix methods improved the material segregation problem and stabilized the quality of LC by increasing viscosity in its fresh grout [10-12]. Barbosa proposed an image processing based technique to evaluate the segregation of LC. The tests showed that using this uniformity analysis might be efficient to classify the aggregate distribution on LC samples [13]. However, these studies mainly focused on properties inherent to LC.

The common volume fraction of coarse aggregates in conventional concrete (CC) is in the range of 35\%-40\% [8]. Compared with CC, LC is well recognized that it requires higher demand of cement grout $[14,15]$. Thus, the high percentage of grout weakens the effect on interlocking and framework structure, which even results in segregation, laitance, and bleeding during the vibrating. As a relatively old 
TABLE 1: Chemical compositions and physical properties of ordinary Portland cement.

\begin{tabular}{lcccccccc}
\hline Label & $\mathrm{SiO}_{2}$ & $\mathrm{Al}_{2} \mathrm{O}_{3}$ & $\mathrm{CaO}$ & $\mathrm{Fe}_{2} \mathrm{O}_{3}$ & $\mathrm{MgO}$ & $\mathrm{SO}_{3}$ & Specific gravity & Fineness $\left(\mathrm{m}^{2} / \mathrm{kg}\right)$ \\
\hline Cement & 20.36 & 5.67 & 62.81 & 3.84 & 2.68 & 2.51 & 3.14 & 329 \\
\hline
\end{tabular}

concrete technique, preplaced aggregate concrete (PAC) has a unique method where preplacing coarse aggregates with high volume are initially packed into the formworks after which grout is injected into the voids [16]. Such void space is effectively filled by the grout, which has a predominant effect on the properties $[17,18]$. This method is of great advantage to allow aggregate particles to increase contact points and interlock with each other, which is unique to promote LC behavior and especially provide a new perspective to solve the aggregate segregation $[19,20]$. The study on the performance of PAC has been a matter of great interest for limited researchers $[20,21]$. The most recent study appears to be Coo and Pheeraphan $[22,23]$, in which they investigated the effect of sand and fly ash on PAC mechanical properties. It was found that optimized proportions of sand and fly ash replacement improve mechanical properties of PAC while no significant effects of coarse aggregate gradation were observed. For further research, they studied reinforced beam shear capacity of PAC. Najjar et al. [24] also attempted to study the damage mechanisms of PAC when exposed to chemical sulfate and physical salt attacks. It showed that PAC specimens exhibited high sulfate resistance. Obviously, previous researches have mainly concentrated on cement replacement materials of PAC grouts. However, there is little information available on the application of PAC used in lightweight concrete. PAC use can make the aggregate particles distribution of the cementitious material reach to the state of dense packing and the relative displacement of aggregate particles will not occur. Thus, the method of preplaced lightweight aggregate concrete (PLC) can be a very effective way to improve the segregation and show better homogeneity in LC.

As stimulated by above facts, this study addresses the use of preplaced casting method in the LC. Two sets of preplaced lightweight aggregate concrete (PLC) and conventional lightweight aggregate concrete (CLC) with three different mixtures are designed to observe the degree of segregation. A series of tests are conducted according to relevant standards to evaluate the properties and performance including compressive strength, unit weight, specific strength, splitting tensile strength, flexural strength, drying shrinkage, and static modulus of elasticity. This modified casting method is applied to find out whether PLC could be suitable for lightweight aggregate compared when it decreases the cement amount.

\section{Experimental Program}

2.1. Materials. All materials used in the experiment included ordinary Portland cement, spherical shale ceramsite used as lightweight aggregate, fine aggregate, cellulose ethers (CE),
TABLE 2: The properties of LA.

\begin{tabular}{lc}
\hline Label & LA \\
\hline Bulk density $\left(\mathrm{kg} / \mathrm{m}^{3}\right)$ & 737 \\
Particle density $\left(\mathrm{kg} / \mathrm{m}^{3}\right)$ & 1350 \\
Cylinder compression strength $(\mathrm{Mpa})$ & 5.8 \\
Water absorption $(\%)$ & $8.8(1 \mathrm{~h})$ \\
& $10.5(24 \mathrm{~h})$ \\
\hline
\end{tabular}

TABLE 3: The grading of LA.

\begin{tabular}{lcccc}
\hline Sieve size $(\mathrm{mm})$ & $<5 \mathrm{~mm}$ & $5 \mathrm{~mm}$ & $10 \mathrm{~mm}$ & $16 \mathrm{~mm}$ \\
\hline Residue on each sieve $(\%)$ & 0.6 & 31.1 & 68.3 & 0 \\
\hline
\end{tabular}

air-entraining agent (AEA), water, and a polycarboxylatebased high range water reducer (HRWR). The chemical compositions and physical properties of cement are presented in Table 1. The fine aggregate used was provided from local river with a fineness modulus of 2.7. The bulk density and absorption capacity of fine aggregate are $1350 \mathrm{~kg} / \mathrm{m}^{3}$ and $1.6 \%$, respectively. The lightweight aggregate used in this research is spherical shale ceramsite with continuous grading. The properties and gradation of LA are shown in Tables 2 and 3. The water used was tap water. As water reducer, the HRWR with a solid content of approximately $45 \%$ was used to achieve the desired better workability for all concrete mixtures.

2.2. Mix Proportions. The two sets of different casting method including CLC (Set 1) and PLC (Set 2) were designed for comparative analysis and CLC was considered as control concrete. Based on the principles of designs of light aggregate concrete mix, different mix proportions were calculated by using absolute volume method according to JGJ12-2006 [25]. The dosage of lightweight aggregate per cubic meter of LC is bulk density of LA. Different strength grades were designed by changing different water to cement ratios. In the case of each set, three water to cement ratios $(0.4,0.45$, and 0.5$)$ were observed. Due to the less grout of PLC used in the experiment, the dosage of grout is decreased and calculated by staying the $\mathrm{w} / \mathrm{c}$ ratio and grout flowability the same. The mix proportion and actual material ratios are shown in Table 4.

2.3. Specimens Preparation and Measurement. The method of casting PLC involves two stages: materials mixing and grouts injection into frames with preplaced lightweight aggregate. The fresh grouts were prepared using the mixture procedure through the study. First, the dry ingredients were initially mixed on a pan type concrete mixer for approximately $5 \mathrm{~min}$. Then the grout mixer started to agitate with the 
TABLE 4: Mix proportions $\left(\mathrm{kg} / \mathrm{m}^{3}\right)$.

\begin{tabular}{lcccccccc}
\hline Mix group & Mix code & Cement & Sand & LA & HRWR & AEA & CE & Water \\
\hline \multirow{3}{*}{ Set (1) } & $1-1$ & 450 & 729 & 737 & 4.50 & 0.05 & 0.23 & 225 \\
& $2-1$ & 450 & 729 & 737 & 4.50 & 0.05 & 0.23 \\
\multirow{4}{*}{ Set (2) } & $3-1$ & 450 & 729 & 737 & 4.50 & 0.05 & 0.23 \\
& $1-2$ & 435 & 705 & 737 & 4.35 & 0.04 & 0.22 \\
& $2-2$ & 435 & 705 & 737 & 4.35 & 0.04 & 0.22 & 180 \\
& $3-2$ & 435 & 705 & 737 & 4.35 & 0.04 & 0.22 \\
\hline
\end{tabular}

TABLE 5: Testing results of compressive strength and unit weight.

\begin{tabular}{lccccccc}
\hline & \multicolumn{3}{c}{$\begin{array}{c}\text { Cubic compressive strength } \\
\text { Mix code }\end{array}$} & & $\begin{array}{c}\text { Axial compressive strength } \\
(\mathrm{MPa})\end{array}$ & $\begin{array}{c}\text { Unit weight } \\
\left(\mathrm{kg} / \mathrm{m}^{3}\right)\end{array}$ \\
& $7 \mathrm{~d}$ & $28 \mathrm{~d}$ & $56 \mathrm{~d}$ & $7 \mathrm{~d}$ & $28 \mathrm{~d}$ & $56 \mathrm{~d}$ \\
\hline $1-1$ & 31.68 & 35.89 & 39.41 & 25.49 & 28.72 & 31.55 & 1820 \\
$1-2$ & 32.55 & 37.10 & 41.82 & 26.16 & 30.30 & 33.47 & 1780 \\
$2-1$ & 32.06 & 37.01 & 40.65 & 27.29 & 32.99 & 33.57 & 1832 \\
$2-2$ & 33.14 & 40.14 & 44.07 & 28.10 & 33.32 & 35.58 \\
$3-1$ & 35.36 & 42.11 & 46.83 & 28.42 & 34.28 & 37.94 & 1792 \\
$3-2$ & 38.73 & 44.31 & 48.71 & 31.31 & 36.87 & 39.36 & 1841 \\
\hline
\end{tabular}

measured water. Homogenized dry ingredients from the concrete mixer were then all loaded into the grout mixer, continually agitating until all dry particles were completely hydrated for approximately $3 \mathrm{~min}$. All admixtures were then added to the mixture and mixed continuously for another 2 min. Specimen samples used for mechanical tests were all collected by injecting grout into frames with preplaced lightweight aggregates. All specimens were then transferred to the curing room and were wrapped with wet burlap when demolded after 24 hours.

Samples for grout compressive strength tested were prepared by pouring the fresh grout into $40 \times 40 \times 160 \mathrm{~mm}$ molds. Concrete specimens were cast into $100 \times 100 \times 100 \mathrm{~mm}$ molds for cubic compressive strength and splitting tensile strength. Molds of $100 \times 100 \times 300 \mathrm{~mm}$ were used for axial compressive strength. In addition, prisms of $100 \times 100 \times$ $400 \mathrm{~mm}$ and prisms of $100 \times 100 \times 515 \mathrm{~mm}$ were used for measuring the flexural strength and drying shrinkage. For the compressive strength, the specimens were tested at a constant rate of a load of $3.0 \mathrm{kN} / \mathrm{s}$. Meanwhile, the compressive load was applied by using a servo-controlled hydraulic testing machine of $1000 \mathrm{kN}$ capacity. The flexural strength was tested at a constant rate of loading $0.1 \mathrm{kN} / \mathrm{s}$ and the splitting tensile strength was at $0.5 \mathrm{kN} / \mathrm{s}$.

\section{Results and Discussion}

3.1. Compressive Strength. The test results for compressive strength including cubic compressive strength and axial compressive strength of CLC and PLC at the age of 7 days, 28 days, and 56 days are shown in Table 5. The results presented are the average value of three specimens from each concrete mix.

Figure 1 shows the overall test results of cubic compressive strength with all mixes up to 56 days. As seen in the figure,

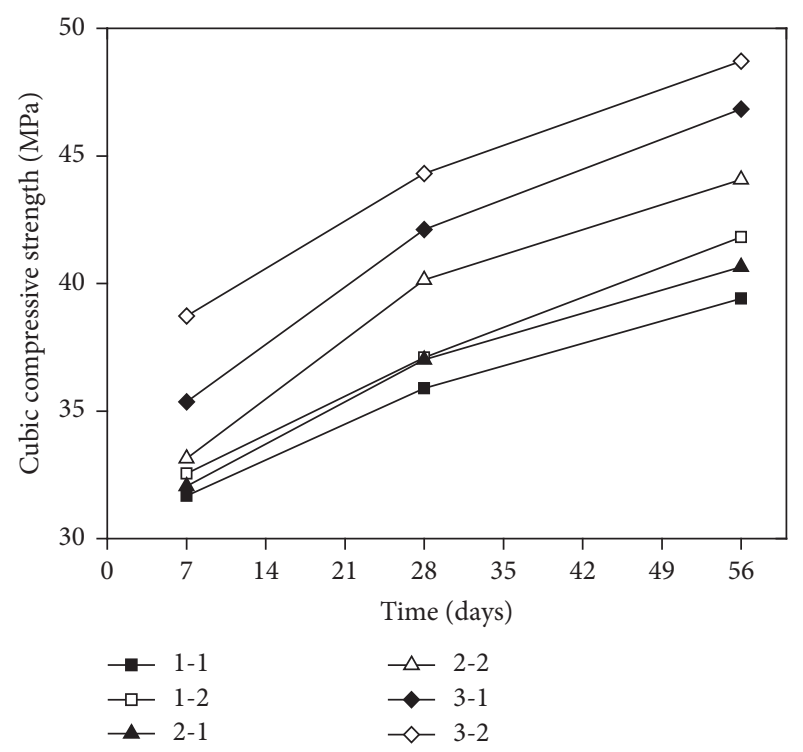

FIgURE 1: Cubic compressive strength of CLC and PLC.

tested PLC compressive strength range attained in the three different $\mathrm{w} / \mathrm{c}$ ratios is from $35.89 \mathrm{MPa}$ to $44.41 \mathrm{MPa}(28$ days of curing time), which is within the strength range of commonly used lightweight aggregate concrete in previous studies [11]. Compared with test results of CLC and PLC, the compressive strength losses of CLC are approximately $3.4 \%$ for $0.5 \mathrm{w} / \mathrm{c}$ ratio, $8.5 \%$ for $0.45 \mathrm{w} / \mathrm{c}$ ratio, and $5.2 \%$ for $0.4 \mathrm{w} / \mathrm{c}$ ratio. PLC mixture incorporating crushed aggregate exhibited a little higher compressive strength than CLC at the same w/c ratio. This may be attributed to the interaction that crushed lightweight aggregates provide better interlock than that of CLC [26, 27]. In Figure 3, it can be seen that the external stresses are transferred through contact 


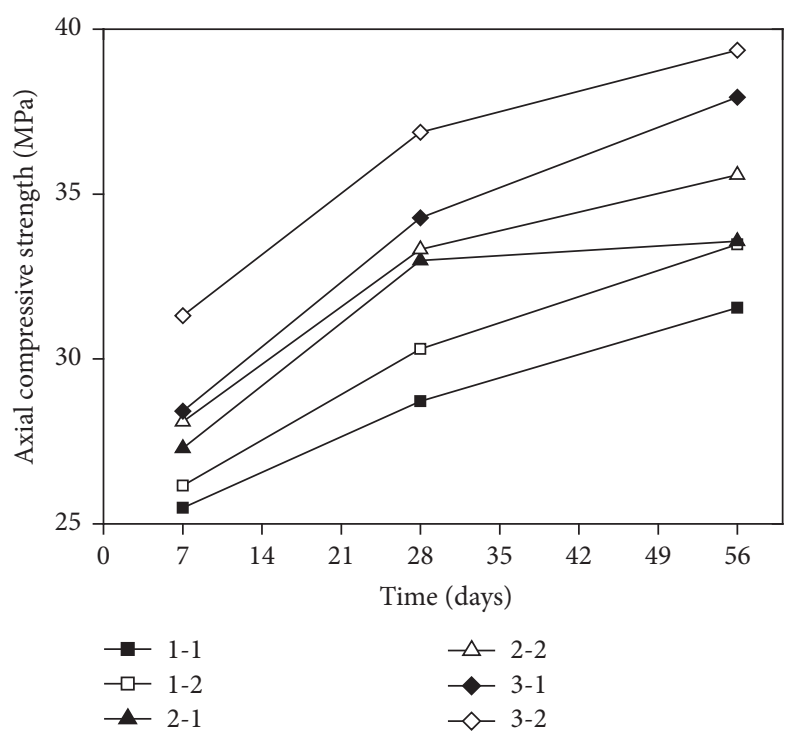

Figure 2: Axial compressive strength of CLC and PLC.
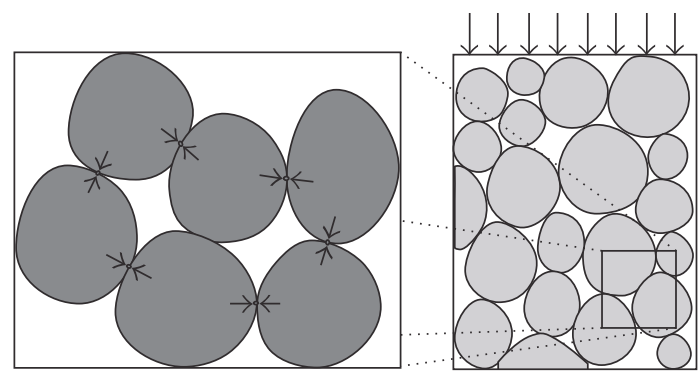

FiguRE 3: Mechanism of transmission of stresses in PLC.

points between aggregate particles due to the specific stress distribution mechanism of PLC. As expected, the interaction of water to cement $(\mathrm{w} / \mathrm{c})$ ratios shows a significant influence on compressive strength. The increase of $\mathrm{w} / \mathrm{c}$ ratios from 0.4 to 0.5 resulted in a gradual decrease in compressive strength, which could be attributed to its great effect on adhesion component. Although using low w/c ratios increases the compressive strength, it will influence the grout flowability. Hence, the water reducer plays a critical role in the strength [28].

The results of axial compressive strength show the same tendency in Figure 2. It can be observed in Table 5 that increasing the $\mathrm{w} / \mathrm{c}$ reduces the axial compressive strength as expected. Meanwhile, PLC mixtures exhibited higher axial compressive strength than that of the controlled conventional mixture.

3.2. Specific Strength. As seen in Table 5, the dry unit weight values of CLC are higher $2.2 \%$ for $0.5 \mathrm{w} / \mathrm{c}$ ratio, $2.2 \%$ for $0.45 \mathrm{w} / \mathrm{c}$ ratio, and $1.7 \%$ for $0.4 \mathrm{w} / \mathrm{c}$ ratio at the age of 28 days than that of PLC, which is due to less grout used in the PLC. As an important measure, specific strength is defined

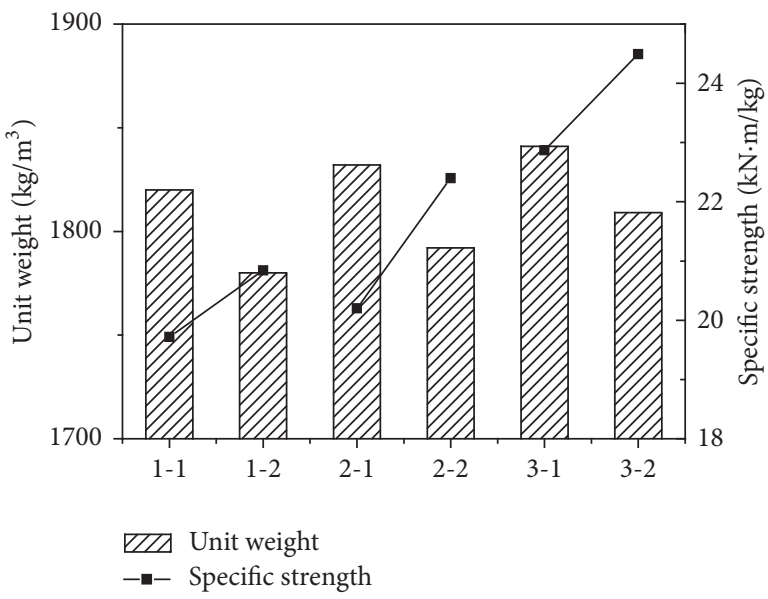

FIGURE 4: Unit weight and specific strength of CLC and PLC.

as the ratio of the cubic compressive strength to the unit weight. It is indicated in Figure 4 that the specific strength of PLC is higher $5.68 \%, 10.89 \%$, and $7.08 \%$, respectively, than CLC at the similar mix design. The value of specific strength is from $20.84 \mathrm{kN} \cdot \mathrm{m} / \mathrm{kg}$ to $24.49 \mathrm{kN} \cdot \mathrm{m} / \mathrm{kg}$, which increased as $w / c$ ratio decreases in concrete mixture. Although the method of PLAC used in the experiment decreases the cement amount, its compressive strength has increase trend. Therefore, PLC shows significant reduction in the weight and excellent properties.

3.3. Splitting Tensile Strength. The splitting tensile strength of concrete refers to the resistant stress capacity of damage crack led by volumetric deformation because of moisture and thermal gradients [29]. The results of splitting tensile strength are listed in Table 6 at the age of 7 days, 28 days, and 56 days. It is indicated that the lower $\mathrm{w} / \mathrm{c}$ ratios increase the splitting tensile strength both in PLC and CLC. However, low w/c ratios may cause a honeycombed structure of particle binding within the lightweight aggregate. Meanwhile, CLC exhibits lower tensile strength than that of PLC with similar mix design in Figure 5. For instance, the average splitting tensile strength of PLC is higher $23 \%$ for $0.5 \mathrm{w} / \mathrm{c}$ ratio, $6.7 \%$ for $0.45 \mathrm{w} / \mathrm{c}$ ratio, and $11.9 \%$ for $0.4 \mathrm{w} / \mathrm{c}$ ratio at the age of 28 days. It was due to the weaker interfacial bond of CLC between lightweight aggregate particles and the cement mixture [20]. The method of PLC used in the experiment not only decreases the cement amount, but also reduces cracks and holes between the lightweight aggregate particles and grout and the steam-fluid port in the frontal zone is also extruded, which shapes a closer union. Moreover, it was also observed that the splitting tensile strength of PLC increased along with the increase of compressive strength, which is similar to properties of CLC.

3.4. Flexural Strength. Figure 6 and Table 6 present the effects of PLC and CLC of three different w/c ratios. PLC flexural strength range in the study is from $2.97 \mathrm{MPa}$ to $4.22 \mathrm{MPa}$ 
TABLE 6: Testing results of splitting tensile strength, flexural strength, and static modulus of elasticity.

\begin{tabular}{|c|c|c|c|c|c|c|c|c|c|}
\hline \multirow[t]{2}{*}{ Mix code } & \multicolumn{3}{|c|}{$\begin{array}{l}\text { Splitting tensile strength } \\
\text { (MPa) }\end{array}$} & \multicolumn{3}{|c|}{ Flexural strength (MPa) } & \multicolumn{3}{|c|}{$\begin{array}{l}\text { Static modulus of elasticity } \\
(\mathrm{GPa})\end{array}$} \\
\hline & $7 \mathrm{~d}$ & $28 \mathrm{~d}$ & $56 \mathrm{~d}$ & $7 \mathrm{~d}$ & $28 \mathrm{~d}$ & $56 \mathrm{~d}$ & $7 \mathrm{~d}$ & $28 \mathrm{~d}$ & $56 \mathrm{~d}$ \\
\hline $1-1$ & 1.82 & 2.68 & 3.09 & 1.95 & 2.97 & 3.34 & 16.81 & 20.58 & 21.18 \\
\hline $1-2$ & 2.32 & 3.29 & 3.63 & 2.37 & 3.51 & 3.82 & 17.21 & 21.26 & 21.79 \\
\hline $2-1$ & 2.38 & 3.30 & 3.74 & 2.45 & 3.38 & 3.69 & 17.93 & 21.83 & 22.22 \\
\hline $2-2$ & 2.47 & 3.52 & 3.89 & 2.58 & 3.74 & 4.01 & 18.08 & 22.43 & 23.05 \\
\hline $3-1$ & 2.53 & 3.69 & 4.11 & 2.70 & 3.83 & 4.18 & 18.41 & 23.17 & 23.64 \\
\hline $3-2$ & 2.70 & 4.13 & 4.57 & 2.86 & 4.22 & 4.57 & 19.94 & 23.75 & 25.01 \\
\hline
\end{tabular}

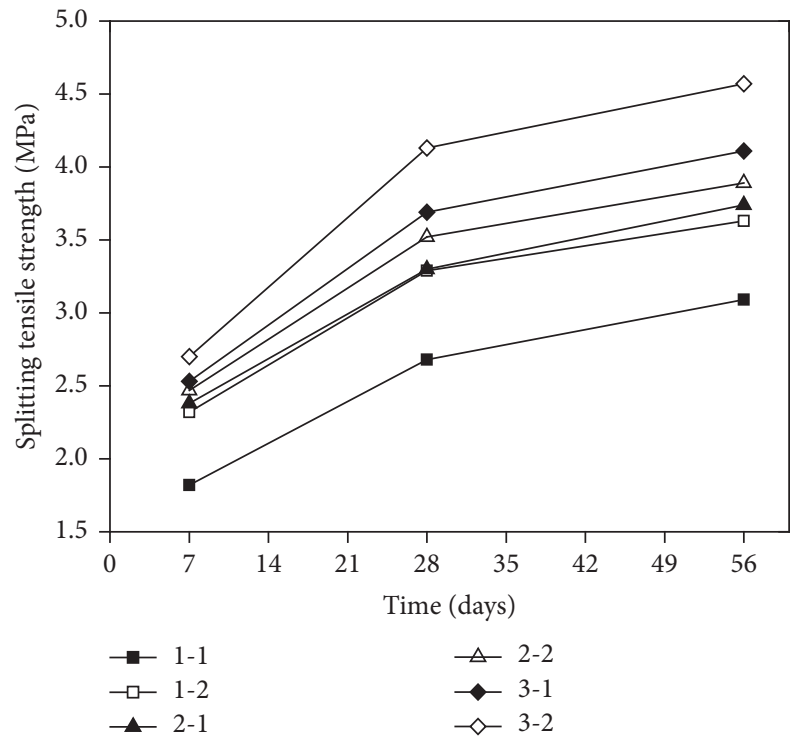

FIGURE 5: Splitting tensile strength of CLC and PLC.

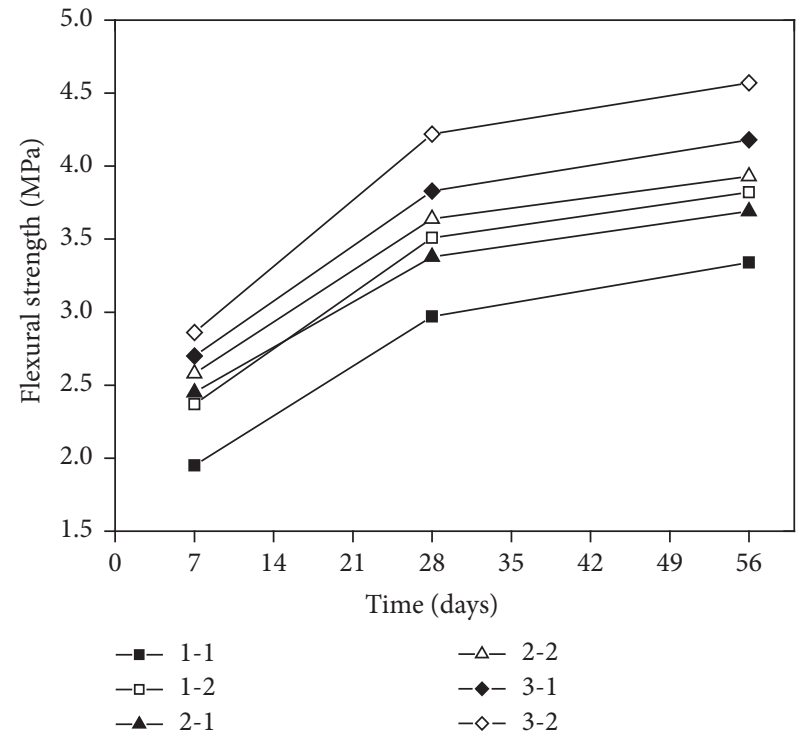

Figure 6: Flexural strength of CLC and PLC. when the w/c ratio decreases from 0.5 to 0.4 ( 28 days of curing time). PLC shows a little higher flexural strength than the behavior of CLC. The mixing method of PLC improves its transition zone structure and makes sure the surface of each particle is covered with a homogeneous binder. It is due to incompletely utilized aggregate strength and the flexural strength relying on harden cement and interface binder; therefore the interaction of each contact point is effective connection $[19,27]$. On the other hand, the data reflects that the flexural strength of PLC and CLC in each mixture has a clear tendency to increase along with the decrease of w/c ratios. Thus the significant factor that affects PAC flexural strength is the $\mathrm{w} / \mathrm{c}$ ratio. The degree of increase of flexural strength at 7 days is greater than 28 and 56 days with continuous hydration process. A milder increase could be observed in flexural strength at higher age especially in the age of 56 days.

3.5. Drying Shrinkage. Shrinkage is generally defined as a volumetric change of the concrete with time owing to physically adsorbed water lost when exposed to a drying environment [30]. The results of different mixtures are plotted in Figure 7.
The shrinkage deformations were generally supposed to be zero at the final setting time and measured drying shrinkage was evaluated up to 90 days. For each mixture, there is an obvious trend that the process of hydration leads to an obvious shrinkage at early ages. This is mainly due to the fact that the amount of cement and water present in the fresh grout decreases when cement hydrates. On the other hand, it should be noted that the shrinkage of PLC as expected was found to be much lower than that of CLC. The increase of shrinkage is approximately $13 \%$ for the CLC and 6\% for PLC when $\mathrm{w} / \mathrm{c}$ ratio ranges from 0.4 to 0.5 . This occurs because the aggregate particles in PLC are reasonably connected and close packed with the interaction of interlock, which compensates the loss of drying shrinkage.

3.6. Static Modulus of Elasticity. The modulus of elasticity is described as an ability to reflect stiffness and deformation. Table 6 summarized the modulus of elasticity of PLC and CLC at different ages. In Figure 8, PLC results in an increase in elastic modulus by approximately $2.5 \%$ of $0.5 \mathrm{w} / \mathrm{c}$ ratio, $2.7 \%$ of $0.45 \mathrm{w} / \mathrm{c}$ ratio, and $3.3 \%$ of $0.4 \mathrm{w} / \mathrm{c}$ ratio at the age of 28 days 


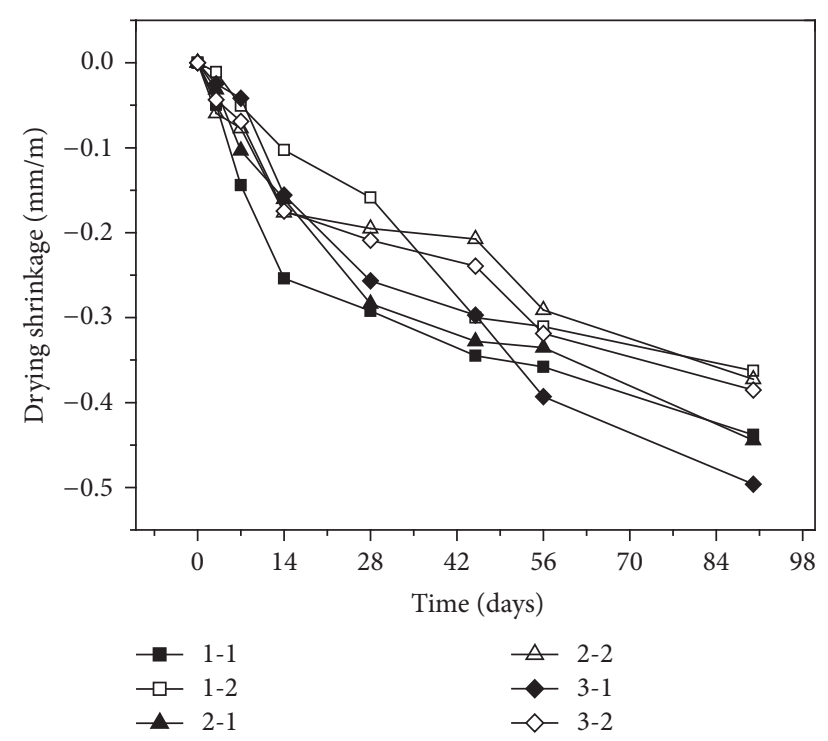

FIGURE 7: Drying shrinkage of CLC and PLC.

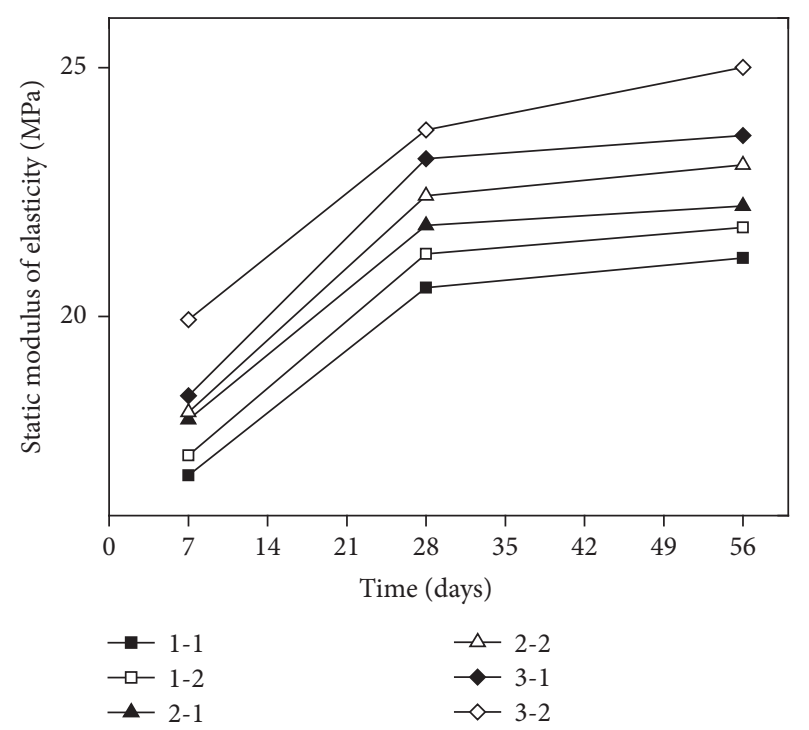

Figure 8: Static modulus of elasticity of CLC and PLC.

compared with CLC. It can be observed that PLC exhibits higher modulus of elasticity than that of CLC for different mixtures. This can be due to the fact that PLC forms a skeleton of lightweight aggregate particles resting on each other. Thus, external loads will transmit through connection points in the static granular piling. Generally, the modulus of elasticity has an affinity for the elastic modulus of its components and the proportion content by volume in concrete [16]. In addition, the elastic modulus of elasticity of coarse aggregates is generally higher than that of cement paste. Consequently, the higher elastic modulus of PLC can be considered as a consequence of the modulus of elasticity of the used coarse aggregate.

\section{Conclusions}

(1) The method of PLC used in the experiment shows higher performance in compressive strength, specific strength, splitting tensile strength, and flexural strength. Thus, PLC shows significant reduction in the weight and better properties.

(2) Compared with test results of CLC and PLC, PLC mixture incorporating crushed aggregate exhibited higher compressive strength than CLC at the same w/c ratio; this can be attributed to the fact that crushed aggregates provide better interlock than that of CLC. Thus, PLC saves the amount of grout on the premise that it shows excellent mechanical properties.

(3) PLC exhibits higher modulus of elasticity than that of CLC for different mixtures. This was attributed to the better interfacial bond between lightweight aggregate particles and the grout mixture, leading to effective connection.

(4) The increase of shrinkage is approximately $13 \%$ for the CLC and $6 \%$ for PLC when w/c ratio ranges from 0.4 to 0.5 . Meanwhile, the shrinkage of PLC was found to be much lower than that of CLC due to the close pack with the interaction of interlock

(5) Above all, the method of PLC provides a better solution for the segregation problem in the LC. PLC does not need vibration to achieve a denser structure, which can in turn save the cost in the practice. Meanwhile, PLC is considered as an effective method for the difficult section to operation and underwater concreting.

\section{Conflicts of Interest}

The authors declare that they have no conflicts of interest.

\section{Acknowledgments}

The research work was supported by China National Research Fund (51379015), Natural Science Foundation Research Project of Shaanxi Province of China (2016JM5044), and Central Universities Fund (310823172001, 310823170213, and 310823170648).

\section{References}

[1] J. N. Farahani, P. Shafigh, B. Alsubari, S. Shahnazar, and H. B. Mahmud, "Engineering properties of lightweight aggregate concrete containing binary and ternary blended cement," Journal of Cleaner Production, vol. 149, pp. 976-988, 2017.

[2] M. R. Hamidian, P. Shafigh, M. Z. Jumaat, U. J. Alengaram, and N. H. R. Sulong, "A new sustainable composite column using an agricultural solid waste as aggregate," Journal of Cleaner Production, vol. 129, pp. 282-291, 2016.

[3] P. Shafigh, M. A. Nomeli, U. J. Alengaram, H. B. Mahmud, and M. Z. Jumaat, "Engineering properties of lightweight aggregate concrete containing limestone powder and high volume fly ash," Cleaner Production, vol. 135, pp. 148-157, 2016.

[4] T. Y. Lo, W. C. Tang, and H. Z. Cui, "The effects of aggregate properties on lightweight concrete," Building and Environment, vol. 42, no. 8, pp. 3025-3029, 2007. 
[5] V. Corinaldesi, A. Mazzoli, and G. Moriconi, "Mechanical behaviour and thermal conductivity of mortars containing waste rubber particles," Materials and Design, vol. 32, no. 3, pp. 1646-1650, 2011.

[6] B.-W. Jo, S.-K. Park, and J.-B. Park, "Properties of concrete made with alkali-activated fly ash lightweight aggregate (AFLA)," Cement and Concrete Composites, vol. 29, no. 2, pp. 128-135, 2007.

[7] H. K. Kim, J. H. Jeon, and H. K. Lee, "Workability, and mechanical, acoustic and thermal properties of lightweight aggregate concrete with a high volume of entrained air," Construction and Building Materials, vol. 29, pp. 193-200, 2012.

[8] Y. Ke, A. L. Beaucour, S. Ortola, H. Dumontet, and R. Cabrillac, "Influence of volume fraction and characteristics of lightweight aggregates on the mechanical properties of concrete," Construction and Building Materials, vol. 23, no. 8, pp. 2821-2828, 2009.

[9] Y. J. Li and J. T. Ding, "Experimental study on the antisegregation performance of pumping high strength lightweight aggregate concrete," Sichuan Building Science, vol. 31, no. 5, pp. 103-107, 2005.

[10] A. Kiliç, C. D. Atiş, E. Yaşar, and F. Özcan, "High-strength lightweight concrete made with scoria aggregate containing mineral admixtures," Cement and Concrete Research, vol. 33, no. 10, pp. 1595-1599, 2003.

[11] M. N. Haque, H. Al-Khaiat, and O. Kayali, "Strength and durability of lightweight concrete," Cement and Concrete Composites, vol. 26, no. 4, pp. 307-314, 2004.

[12] J. A. Rossignolo and M. V. C. Agnesini, "Mechanical properties of polymer-modified lightweight aggregate concrete," Cement and Concrete Research, vol. 32, no. 3, pp. 329-334, 2002.

[13] F. S. Barbosa, A.-L. Beaucour, M. C. R. Farage, and S. Ortola, "Image processing applied to the analysis of segregation in lightweight aggregate concretes," Construction and Building Materials, vol. 25, no. 8, pp. 3375-3381, 2011.

[14] K. H. Mo, T. C. Ling, U. J. Alengaram, S. P. Yap, and C. W. Yuen, "Overview of supplementary cementitious materials usage in lightweight aggregate concrete," Construction and Building Materials, vol. 139, pp. 403-418, 2017.

[15] J. Alexandre Bogas, M. G. Gomes, and S. Real, "Capillary absorption of structural lightweight aggregate concrete," Materials and Structures, vol. 48, no. 9, pp. 2869-2883, 2015.

[16] H. S. Abdelgader and J. Górski, "Stress-strain relations and modulus of elasticity of two-stage concrete," Journal of Materials in Civil Engineering, vol. 15, no. 4, pp. 329-334, 2003.

[17] H. S. Abdelgader, J. Górski, J. Khatib, and A. S. El-Baden, “Twostage concrete: effect of silica fume and superplasticizers on strength," Concrete Plant and Precast Technology, vol. 82, no. 3, pp. 38-47, 2016.

[18] A. S. M. Abdul Awal and I. A. Shehu, "Performance evaluation of concrete containing high volume palm oil fuel ash exposed to elevated temperature," Construction and Building Materials, vol. 76, pp. 214-220, 2015.

[19] A. Nowek, P. Kaszubski, H. S. Abdelgader, and J. Górski, "Effect of admixtures on fresh grout and two-stage (pre-placed aggregate) concrete," Structural Concrete, vol. 8, no. 1, pp. 17-23, 2007.

[20] M. F. Najjar, A. M. Soliman, and M. L. Nehdi, "Critical overview of two-stage concrete: properties and applications," Construction and Building Materials, vol. 62, pp. 47-58, 2014.

[21] H. S. Abdelgader and A. A. Elgalhud, "Effect of grout proportions on strength of two-stage concrete," Structural Concrete, vol. 9, no. 3, pp. 163-170, 2008.
[22] M. Coo and T. Pheeraphan, "Effect of sand, fly ash and limestone powder on preplaced aggregate concrete mechanical properties and reinforced beam shear capacity," Construction and Building Materials, vol. 120, pp. 581-592, 2016.

[23] M. Coo and T. Pheeraphan, "Effect of sand, fly ash, and coarse aggregate gradation on preplaced aggregate concrete studied through factorial design," Construction and Building Materials, vol. 93, pp. 812-821, 2015.

[24] M. Najjar, M. Nehdi, A. Soliman, and T. Azabi, "Damage mechanisms of two-stage concrete exposed to chemical and physical sulfate attack," Construction and Building Materials, vol. 137, pp. 141-152, 2017.

[25] JGJ12-2006, Technical Specification for Lightweight Aggregate Concrete Structures, China Standard Publishing House, Hebei, China, 2006.

[26] H. S. Abdelgader, "Effect of the quantity of sand on the compressive strength of two-stage concrete," Magazine of Concrete Research, vol. 48, no. 177, pp. 353-360, 1996.

[27] H. S. Abdelgader, "How to design concrete produced by a twostage concreting method," Cement and Concrete Research, vol. 29, no. 3, pp. 331-337, 1999.

[28] W. Sun, H. Yan, and B. Zhan, "Analysis of mechanism on waterreducing effect of fine ground slag, high-calcium fly ash, and low-calcium fly ash," Cement and Concrete Research, vol. 33, no. 8, pp. 1119-1125, 2003.

[29] M. L. Nehdi and A. M. Soliman, "Early-age properties of concrete: overview of fundamental concepts and state-of-the art research," Construction Materials, vol. 164, pp. 55-77, 2011.

[30] A. Bentur, S.-I. Igarashi, and K. Kovler, "Prevention of autogenous shrinkage in high-strength concrete by internal curing using wet lightweight aggregates," Cement and Concrete Research, vol. 31, no. 11, pp. 1587-1591, 2001. 

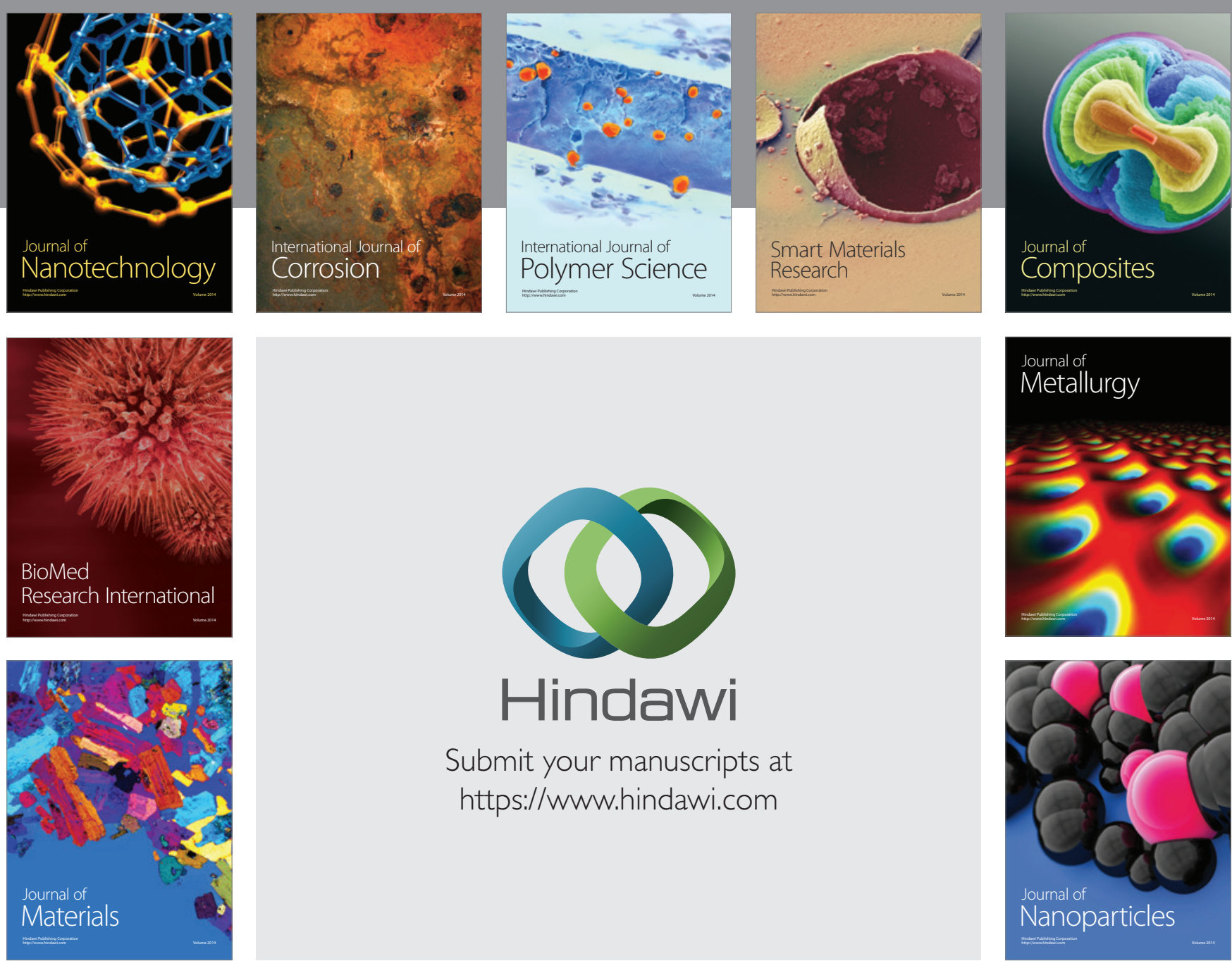

\section{Hindawi}

Submit your manuscripts at

https://www.hindawi.com

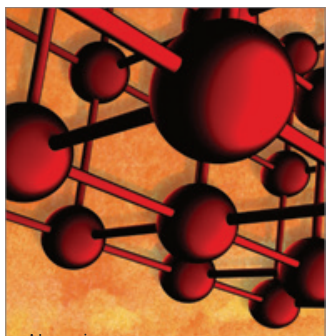

Materials Science and Engineering
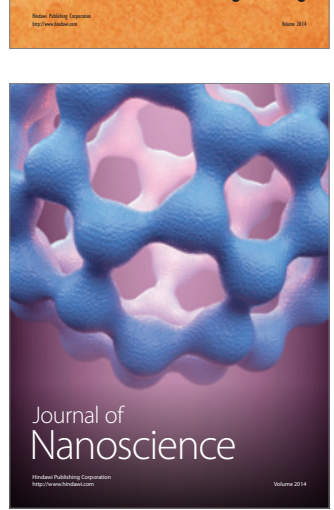
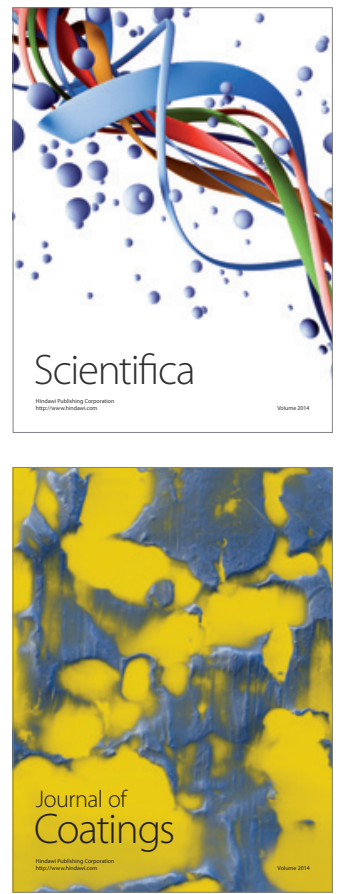
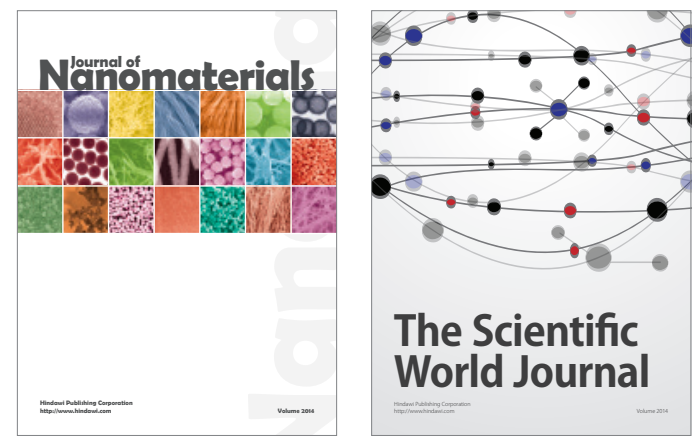

The Scientific World Journal
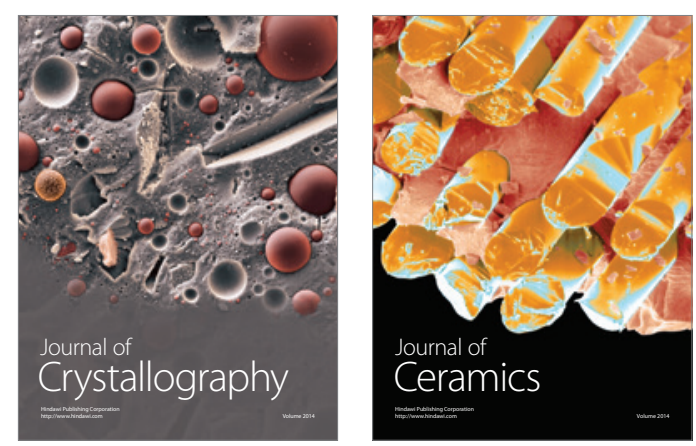
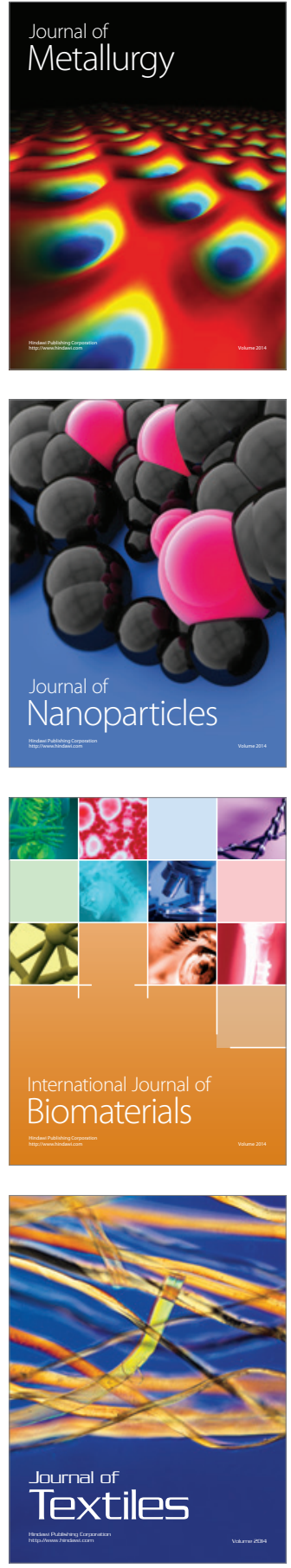